\title{
HVA SYKEPLEIERE BøR VITE OM MALARIA
}

Nyttig. Alle sykepleiere bør ha basiskunnskap om sykdommen.

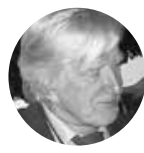

Bjørn Myrvang, Overlege/professor emeritus. Kompetansesenter for import- og tropesykdommer OUS, Ullevål

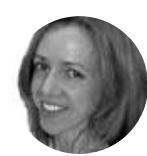

Mona Hjønnevåg Joof, Konsulent/

klinisk spesialist sykepleie

Kompetansesenter for import- og tropesykdommer, OUS, Ullevål

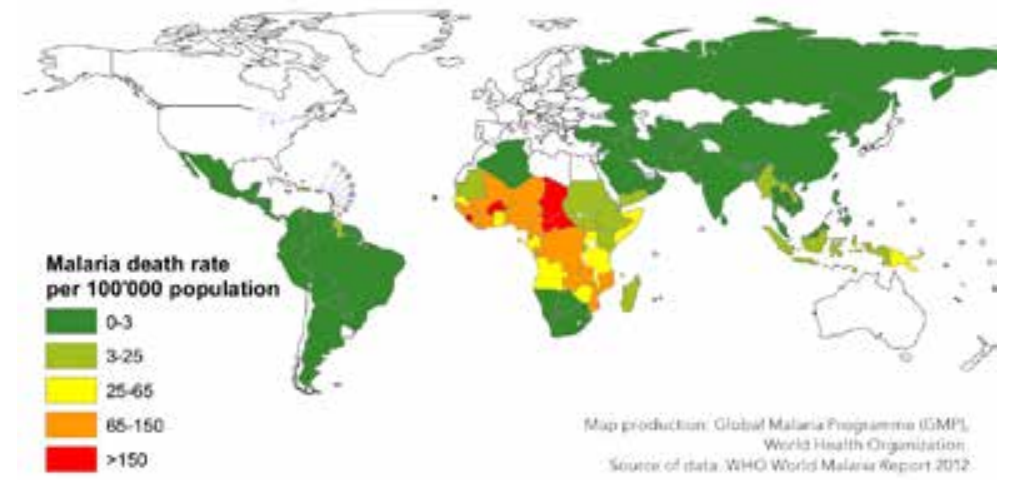

Figur 1: Kartet viser dødsfall av malaria i ulike områder av verden, basert på tall fra Verdens helseorganisasjon (2012). Høyest antall dødsfall pr. 100.000 innbyggere ble registrert i Tsjad, Den sentralarikanske republikk, Burkina Faso og i Sierra Leone (rød farge), men høye dødstall ble også funnet i en rekke andre landi Afrika (oransje farge). som reiser ut for arbeide i områder hvor malaria er et helseproblem, ha skikkelige malariakunnskaper.

MANGELFULLT. Vi har erfart at undervisningen om malaria ved våre høyskoler har vært og fortsatt kan være svært mangelfull, og det er derfor grunn til å anta at mange sykepleiere har beskjedne kunnskaper om sykdommen. En del lærebøker i sykdomslære, som er i bruk, inneholder lite informasjon om malaria. Imidlertid finnes det lærebøker som gir en god om enn ikke helt oppdatert beskrivelse av sykdommen (1,2). Formålet med områder med mistanke om malaria. Framfor alt må sykepleiere denne artikkelen er å gi en kortfattet, korrekt og oppdatert orientering om malaria. Samtidig vil leserne ved å gå til referansene, kunne få utdypet sine kunnskaper, om man føler behov for det.

UTBREDELSE. Malaria er utbredt over store deler av den tropiske verden. Afrika er hardest rammet, men infeksjonen er også et problem i områder i Asia, Oceania og i noen grad i Sør- og Mellom-Amerika. Verdens helseorganisasjon har beregnet at det i 2012 var 207 millioner tilfeller og 627000 dødsfall på grunn av malaria $(3,4)$. Det er tall som er lavere enn tidligere beregninger. De fleste som dør, er barn i Afrika (se figur 1). Stor usikkerhet er knyttet til tallene, men det er sikkert at både antall malariatilfeller og dødsfall i flere områder har gått betydelig ned de siste åra. Samtidig har nok forekomsten økt i noen områder, og dessuten må vi være klar over at mangelfull registrering og underrapportering er et problem, noe blant annet undersøkelser i India har vist (5).

NYTT. Det har i snart hundre år vært kjent at fire plasmodier kan gi malaria hos mennesket: Plamodium falciparum, Plamodium vivax, Plamodium ovale og Plamodium malariae. De aller fleste dødsfall skyldes infeksjoner med
Fakta 000

Hoved-

budskap

Malaria er en av verdens viktigste infeksjonssykdommer. Mange sykepleiere trenger grundige oppdaterte kunnskaper om sykdommen, noe som ofte ikke finnes i lærebøker. Artikkelen gir kunnskap både om epidemiologi i verden og i Norge, diagnostikk, behandling og profofylakse, slik situasjonen er i2015.

\section{Nøkkelord.}

Les mer og finn litteraturhenvisninger på våre nettsider

- Infeksjonssykdom

- Epidemiologi

- Internasjonal helse 


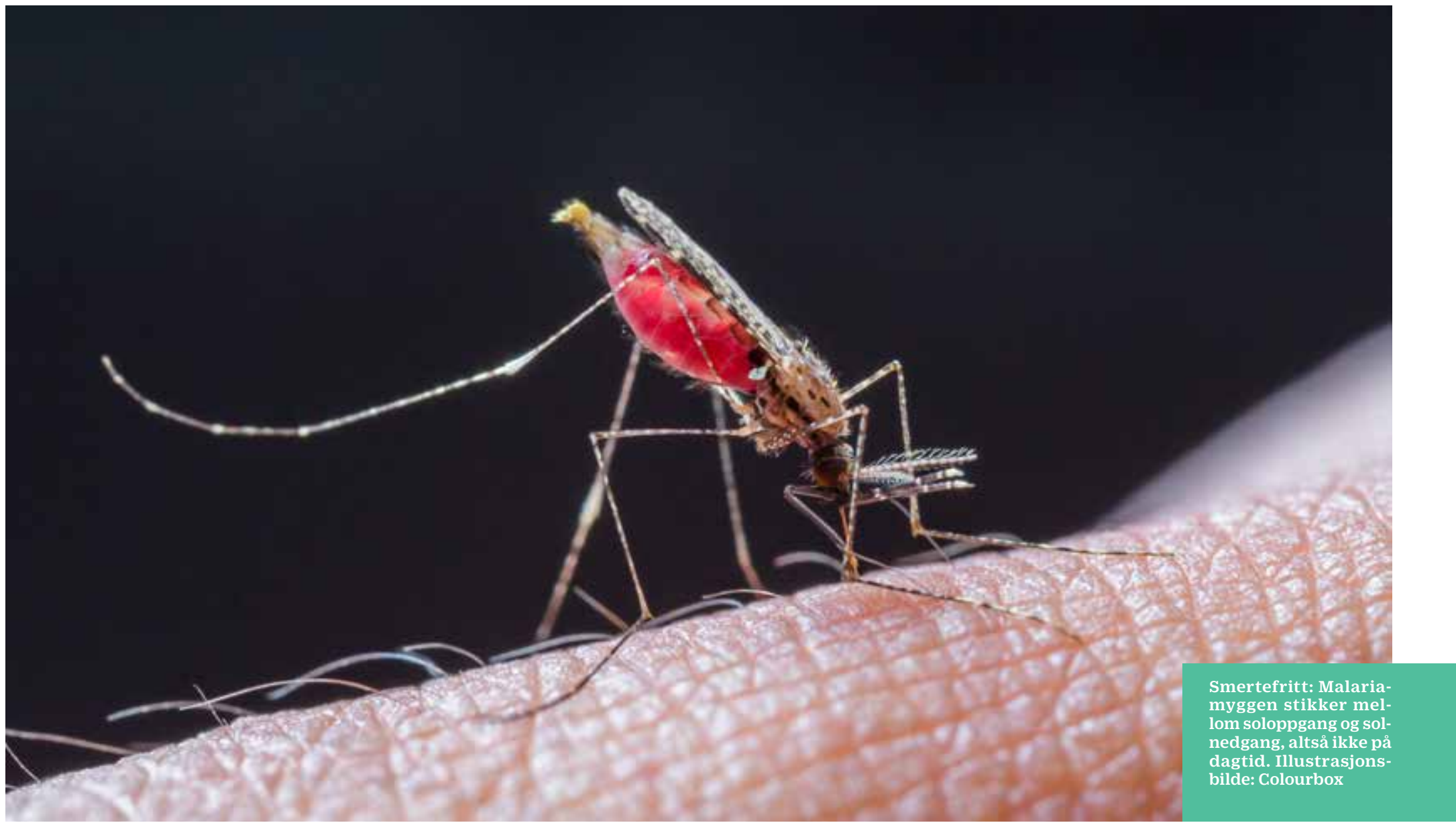

P. falciparum, men infeksjon med P. vivax kan også en sjelden gang gi et alvorlig forløp og dødelig utfall. Relativt nylig er det vist at også en femte plasmodiumart, P. knowlesi, kan gi malaria hos mennesker. P. knowlesi infiserer vanligvis aper, og det var først i 2004 det ble dokumentert at parasitten også kan forårsake sykdom og død hos mennesker (6). De fleste tilfeller er diagnostisert i den del av Malaysia som ligger på øya Borneo, men P. knowlesi-infeksjon er etter hvert diagnostisert i flere land i SørøstAsia. Det har også vært flere rapporter om at personer som har vært på besøk i disse områdene, er blitt infisert med P. knowlesi (7).

NORGE. En del personer bosatt i Norge pådrar seg malaria ved besøk i malariaområder. I de fleste tilfeller er infeksjonen ervervet i
Afrika, sør for Sahara. Risikoen for smitte er generelt langt mindre i andre verdensdeler. På slutten av 1990-tallet ble det årlig meldt over 100 malariatilfeller til Meldesystem for infeksjonssykdommer (MSIS), mens tallet senere har ligget på mellom 30 og 40. Av til dels ukjente grunner steg antall meldte tilfeller til 87 i 2013 og til 120 i 2014. Noe av forklaringen kan være at legene ble flinkere til å overholde meldeplikten de to siste årene, etter iherdig innsats fra MSIS-ansatte. De fleste malariatilfeller vi ser i Norge skyldes P. falciparum, som er den dominerende malariaparasitten i Afrika (8). Det har skjedd dødsfall på grunn av malaria i Norge, men det er en sjeldenhet. Mangelfull profylakse og for sent innsatt korrekt behandling har vært årsakene til dødsfallene. Det kan ikke sterkt nok understrekes at rask diagnostikk etter symptomdebut og innsetting

\section{«Malaria er utbredt over store deler av den tropiske verden.»}

av korrekt behandling er meget viktig for å unngå alvorlig sykdomsutvikling ved falciparuminfeksjon (9). I tillegg til falciparuminfeksjoner ser vi hvert år noen tilfeller av infeksjon med P. vivax, mens vi sjelden ser infeksjoner med P. ovale og P. malariae. P. knowlesi er foreløpig ikke diagnostisert i Norge.

SMITTE. Malaria smittes gjennom stikk av hunnmygg av arten Anopheles. Myggen stikker mellom solnedgang og soloppgang, det vil si ikke på dagtid. Stikkene er smertefrie. Den viktigste måten å unngå malaria på er derfor at man unngår å få stikk av anophelesmyggen. Man kan også få malaria dersom man får transfundert blod fra en person som har malariaparasitter i blodet.

SYMPTOMER. Det tar ti dager eller mer fra man blir smittet til man får sykdomstegn, vanligvis med feber som hovedsymptom. Ved infeksjon med P. falciparum og P. vivax skal febertoppene komme hver 48 time, men det er slett ikke alltid tilfelle. I første fase av sykdommen kommer febertoppene ofte nokså uregelmessig, særlig ved falciparuminfeksjon. Feber og feberrelaterte 
symptomer, som for eksempel muskelsmerter og hodepine, dominerer sykdomsbildet initialt ved alle former for malaria, men ved falciparuminfeksjon (og også ved infeksjon med P. knowlesi) kan sykdomsbildet raskt og dramatisk endre seg. Pasienten kan få alvorlige sykdomstegn fra en rekke organer. Særlig fryktet er utvikling av hjernemalaria. Det faller oftest sammen med at parasittmengden i blodet når et høyt nivå. Dersom adekvat behandling ikke innsettes raskt, vil det være betydelig mortalitet ved infeksjoner med P. falciparum og P. knowlesi (10).

DIAGNOSTIKK. Man skal ikke stille malariadiagnosen på grunnlag av kliniske symptomer og sykdomstegn. Sikker diagnose kan stilles på følgende to måter:

Mikroskopi. Man påviser malariaparasitter ved mikroskopi av såkalt tykk og tynn dråpe. Dette er den beste metoden, men krever erfaring og utstyr. Man lager tykk og tynn dråpe fra pasientens blod (11). I den tykke dråpen, hvor de røde blodlegemene blir hemolysert, kan man undersøke en relativt stor blodmengde, og erfarne mikroskopører bruker den tykke dråpen til å avgjøre om en pasient har malaria. Er malariadiagnosen stilt, er den tynne dråpen (blodutstryket) best egnet til å avgjøre hvilken plasmodiumtype

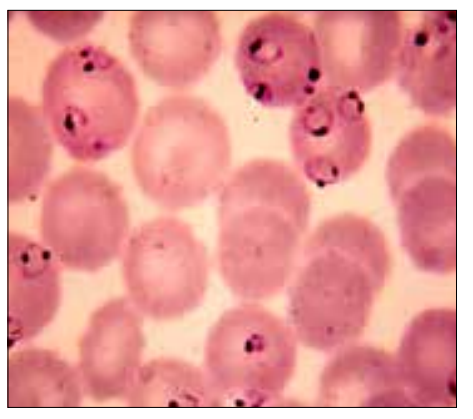

Figur 2: Bildet viser tynn dråpe (blodutstryk) fra dramatisk syk pasient med malaria. Vi ser røde blodlegemer som inneholder malariaparasitter (P.falciparum). pasienten er infisert med. Det har betydning for hvilken behandling man skal velge. Ved falciparuminfeksjon vil mengden parasitter i prøven si oss mye om alvorligheten i sykdomsbildet, og være bestemmende for om vi skal velge peroral eller parenteral behandling (12). Figur 2 viser blodutstryk med stor mengde plasmodier i form av ringer (trofozoitter) i røde blodlegemer. Skal en slik pasient reddes, må han eller hun få parenteral behandling med artesunate eller kinin og annen påkrevet behandling (se figur 2).

Antigenpåvisning. Malariadiagnosen kan også stilles ved å bruke hurtigtester som påviser antigen fra malariaparasittene i blod. Slike tester ble innført for om lag 20 år siden, og blir stadig bedre. For laboratoriepersonell er testene lette å utføre, og krever ikke utstyr. Man får raskt svar, og en stor mengde prøver kan undersøkes på kort tid. Dette er en fordel i land hvor malariaforekomsten er høy. I Norge vil bruk av hurtigtester være særlig aktuelt på sykehus som mangler leger og bioingeniører med erfaring i mikroskopisk malariadiagnostikk (13).

Ulempene med hurtigtester er at de er kvalitative tester, som ikke forteller oss hvor mye parasitter det er i blodet, og at testene kan gi negativt resultat når parasittmengden er lav. Dessuten kan testene bare i begrenset grad fortelle oss hvilken parasitt pasienten er infisert med, men det viktige er at mange hurtigtester kan skille mellom P. falciparum og de andre artene. Og det er slike tester som bør finnes på norske sykehus (13).

BEHANDLING. Hvilken plasmodiumart pasienten er infisert med, og alvorligheten i sykdomsbildet, er avgjørende for hvilken medikamentell behandling man velger (12). I utgangspunktet behandler man infeksjoner med P. falciparum og P. knowlesi likt, og infeksjoner med de andre tre parasittene på en annen måte. I stor grad følger vi WHOs anbefalinger og europeiske retningslinjer i våre behandlingsopplegg $(14,15)$. Ved mindre alvorlige falciparuminfeksjoner foretrekker vi behandling med kombinasjonstabletter (ACT), hvor det ene medikamentet er et artemisininderivat (12). I Norge er ingen ACT-preparater registrert, men mange avdelinger har nok slike tabletter i beredskap. Alternative medikamenter til behandling av denne pasientgruppen er de registrerte preparater meflokin (Lariam) og atovakvon - proguanil (Malaraone, Provaqomyl). Alvorlige syke falciparumpasienter må ha parenteral behandling. Det beste medikament er artesunate (12,15), som er et artemisininderivat, men kinin kan også brukes. Alle norske sykehus som tar imot

«En del personer bosatt i Norge pådrar seg malaria ved besøk i malariaområder.» akutt syke pasienter, må ha ett av disse to medikamentene tilgjengelig. Fortrinnsvis artesunate, da kinin er noe mindre effektivt og har potensielt alvorlige bivirkninger. Pasienter med alvorlig malaria vil i tillegg ofte trenge intensiv behandling som kan innbefatte væskebehandling, respiratorbehandling, dialyse og så videre. (15). Er man i den minste tvil om hvilken parasitt pasienten er infisert med, bør pasienten behandles som en falciparumpasient, spesielt hvis han eller hun har pådratt seg infeksjonen i Afrika. Infeksjoner med P. vivax, P. ovale og P. malariae kan fortsatt behandles med klorokin tabletter. P. vivax- og $\mathrm{P}$. ovaleinfeksjoner skal i tillegg behandles med primakin, for å utrydde hvilende parasitter i leveren (12).

PROFYLAKSE. Å unngå myggstikk er absolutt det viktigste man kan gjøre for å unngå smitte. I malariaendemiske områder har derfor bruk av impregnerte myggnett nattetid fått stor utbredelse, og har sikkert spilt en vesentlig rolle når antall malariatilfelle er blitt 
redusert (16). Myggnettbruk blir ofte kombinert med innendørs spraying for å drepe malariamyggen. Myggnett og innendørs spraying er også aktuelt for turister, særlig hvis man skal bo enkelt i områder med høy malariaforekomst i Afrika. Oppholder man seg utendørs, er det viktig at man på kveldstid bruker klær som dekker mest mulig naken hud. I tillegg må man bruke myggmidler på huden. De mest effektive er midler som inneholder N, N-dietyl-metatoluamid (DEET) eller icaridin (Autan). En del reisende vil i tillegg trenge medikamentell profylakse. Det gjelder særlig reisende til Afrika sør for Sahara, hvor risikoen er stor for å pådra seg falciparuminfeksjon. Hvorvidt reisende til andre verdensdeler behøver medikamentell profylakse, er omdiskutert. Norske og svenske retningslinjer for malariaprofylakse går inn for meget begrenset bruk av medikamentell profylakse hvis man reiser til malariaendemiske områder i andre verdensdeler enn Afrika (17,18). Medikamenter man bruker til profylakse må ha god effekt mot P. falciparum, og vi har tre medikamenter å velge mellom:

- Meflokin, registrert som Lariam. Ulempen med meflokin er at enkelte kan få ubehagelige bivirkninger ved bruk, men de fleste kan bruke middelet uten å få problemer.

- Atovakvon + proguanil, registrert som Malarone og Provaqomyl. Prisen har vært en viktig ulempe ved Malaraone, men er betydelig redusert i 2014 etter at Provaqomyl kom på markedet.

- Doxicyclin, som er et antibiotikum, er ikke mye foreskrevet til malariaprofylakse i Norge, men den beskyttende effekten er antakelig på linje med de to andre alternativene.

VAKSINE. I over 30 år har man gjort iherdige forsøk på å lage en effektiv vaksine mot P. falciparuminfeksjon, men med lite hell. I øyeblikket er cirka 20 vaksine- kandidater i et eller annet trinn av utprøvning. Glaxo-Smith-Kline (GSK), i samarbeid med «Bill \& Melinda Gates Foundation", er kommet lengst. Målgruppen for deres vaksine er barn i Afrika. Vaksinen er den første vaksinen som i omfattende undersøkelser har vist beskyttende effekt, men effekten er ikke så god som man i utgangspunktet håpet. Det er foreløpig ikke avgjort om vaksinen blir godkjent for markedsføring (19). •

\section{REFERANSER:}

1. Bruun Wyller V. Sykdommer knyttet til infeksjonsforsvaret I: Det friske og det syke menneske. Oslo: Cappelen Damm Akademisk, 2014: 923-25.

2. Ørn S, Mjell J, Bach-Gansmo E. Sykdom og behandling. s. 89. Oslo: Gyldendal Akademisk, 2011.

3. WHO. Malaria. Fact sheet Fact sheet No94, Updated March $2014 \mathrm{http}: / / \mathrm{www} . w h o . i n t / m e d i a c e n t r e / f a c t s h e e t s / \mathrm{fs} 094 /$ en/ (6.10.2014).

4. World Malaria Report 2013, side 55-68, WHO, Geneva 2013. www.who.int/malaria/publications/world_malaria_report_2013/en/ (1.10.2014).

5. Haya SI, Gethinga PW, Snow RW. Indiass invisible malaria burden. The Lancet, 2010; 376:1716-17.

6. Myrvang, B. En femte plasmodiumart som kan gi malaria. Tidsskr Nor Legeforen 2010; 130:282-3.

7. Müller M, Schlagenhauf P. Plasmodium knowlesi in travellers, update 2014. Int J Infect Dis. 2014;22: 55-64.

8. 10 Facts on Malaria in Africa - WHO | Regional Office for Africa. www.afro.who.int/ .../malaria/ .../2287-10-factson-malaria-in-africa.html (1.10.2014).

9. Moore DA, Jennings RM, Doherty TF, et al. Assessing the severity of malaria. BMJ 2003; 326:808-9.

10. Sarkar PK, Ahluwalia G, Vijayan VK, Talwar A. Critical care Sarkar PK, Ahluwalia G, Vijayan VK, Talwar A. Critical care
aspects of malaria. I Intensive Care Med. 2010; 25: 93-103. 11. Myrvang B. Malaria i Norge - diagnostikk, behandling og profylakse. Tidsskr Nor Lægeforen 2000; 120:1648-52. 12. Mørch K, Myrvang B. Medikamentell behandling av malaria i Norge. Tidsskr Nor Legeforen 2012; 132: 664-7.

13. Myrvang B, Sannes M. Bruk av malaria hurtigtester ved norske sykehus. Bioingeniøren 2014; Under trykking.

14. World Malaria Report 2013, side 40-47. WHO Geneva 2013. http://www.who.int/malaria/publications/world_malaria_report_2013/en/(2.10.2014).

15. Askling HH, Bruneel F, Buchard $\mathrm{G}$ et al. Management of imported malaria in Europe. Malaria Journal 2012;11: 328. 16. Choi HW, Breman JG, Teutsch SM, The effectiveness of insecticide-impregnated bed nets in reducing cases of malaria infection: a meta-analysis of published results. Am J Trop Med Hyg. 1995; 52: 377-82.

Am JTrop Med Hyg. 1995; 52: 377-82.
17. Forebygging av malaria hos reisende. 2. utgave. Folkehelseinstituttet, Oslo. http://www.fhi.no/ eway/default.aspx?pid=239 \& trg=Main_6157 \& Main_6157=7139:0:25,8802 (2.10.2014).

18. Bouchie A. GSK plows ahead with EMA malaria vaccine submission. Nature Biotechnology. 2013; 31:1066.

\section{FAGARTIKLER:}

Fagartikler kan sendes til

torhild.apall@sykepleien.no

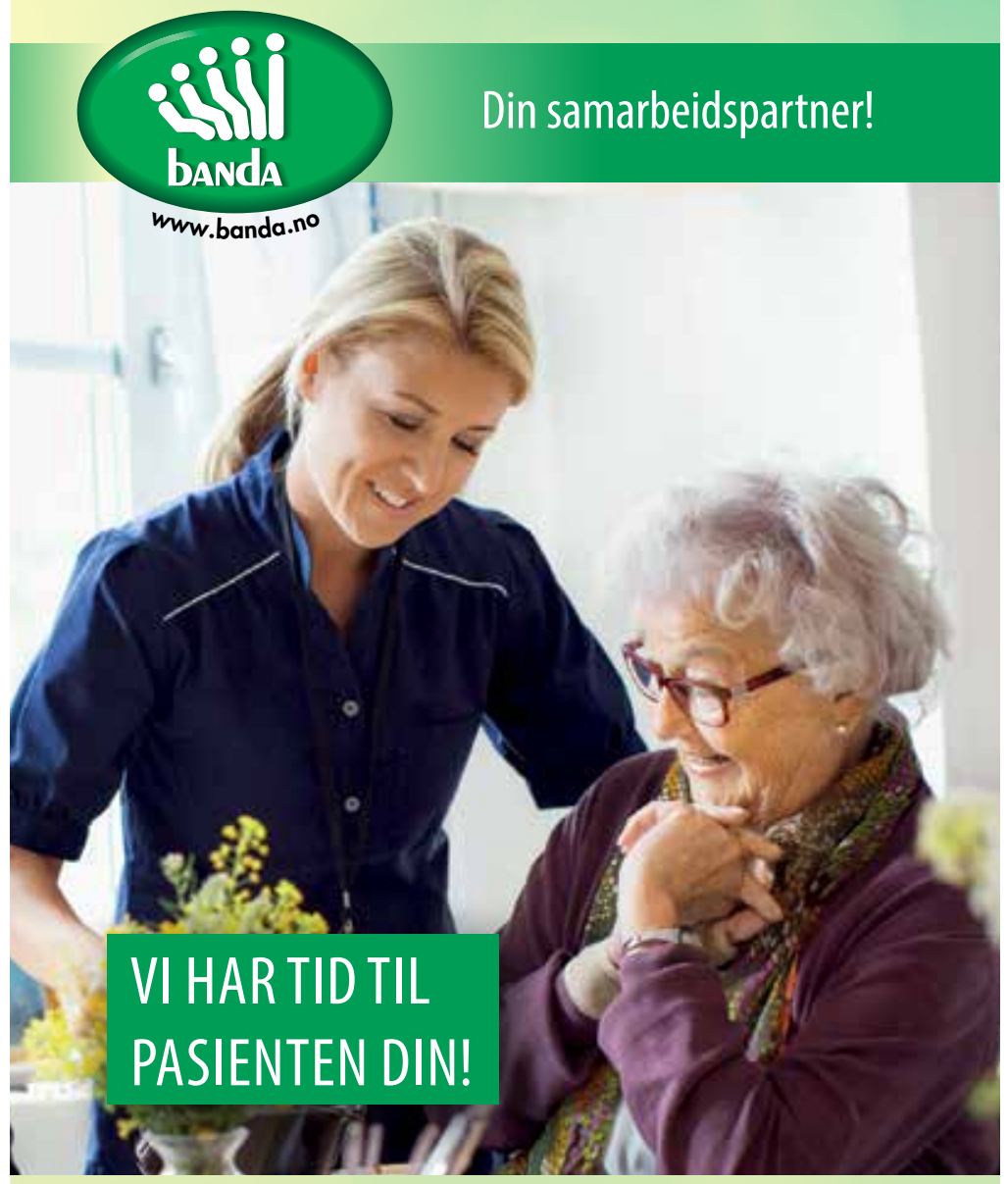

\section{UTSTYR PÅ BLÅRESEPT}

\section{Banda er en kjede med 54 butikker over hele landet med høyt kvalifiserte helsearbeidere. Vi har bl.a. kompetanse innen stomi, inkontinens, ernæring, fiksering og urinretensjon.}

- råd og veiledning i våre samtalerom, eller ved hjemmebesøk til dine pasienter

- tilpasning/valg av utstyr i samarbeid med deg

- hjelp ved sår hud, lukt, brokk og lekkasje

- tilpasset utlevering av utstyr

- hjemkjøring av varer er en selvfølge

Finn nærmeste Bandabutikk på www.banda.no Besøk vår nettbutikk: www.banda.no/nettbutikk Følg oss på Facebook/bandakjeden Bandas hovedkontor: 23384858

H USK!- det er pasientene som eier blåresepten. De kan fritt velge den bandagist/apotek de mener gir den beste service og oppfølging. Vi har blåresept ekspedering via mail på www.banda.no 